\title{
O TRABALHO DO PROFESSOR EBTT: ENTRE A EXIGÊNCIA DO CAPITAL E A POSSIBILIDADE HUMANA
}

\author{
EL TRABAJO DEL PROFESOR EBTT: ENTRE LA EXIGENCIA DEL \\ CAPITAL Y LA POSIBILIDAD HUMANA
}

\section{THE VOCATIONAL EDUCATION TEACHER'S WORK: BETWEEN CAPITAL DEMANDS AND HUMAN POSSIBILITY}

\author{
Jorge Washington de AMORIM JUNIOR ${ }^{1}$ \\ Vanderléia de L. Dal Castel SCHLINDWEIN ${ }^{2}$ \\ Luís Alberto Lourenço de MATOS ${ }^{3}$
}

RESUMO: Este artigo tem como objetivo discutir o trabalho do professor do Ensino Básico, Técnico e Tecnológico (EBTT) do Instituto Federal Educação, Ciência e Tecnologia de Rondônia (IFRO), a partir da análise do Regulamento da Atividade Docente (RAD), buscando compreender sua relação com as demandas do sistema neoliberal e o modelo gerencial na educação. Como suporte para nosso estudo, buscamos fundamentos em alguns conceitos de Dejours (2007), tais como sofrimento e prazer no trabalho, de Bauman (2005) sobre a modernidade, de Antunes e Praun (2015) saúde e trabalho e Sennett (2009) consequências do novo capitalismo para a personalidade do trabalhador. Além disso, trazemos Pacheco (2010) para discutir as questões relacionadas aos Institutos Federais de Educação, Ciência e Tecnologia e os Professores EBTT, bem como a Lei de criação dos Institutos Federais - Lei $n^{\circ} 11.892 / 2008$. Esta pesquisa caracteriza-se como uma pesquisa bibliográfica-documental que, além do levantamento teórico dos conceitos relacionados, analisou a Resolução no 33/2017 que instituiu o RAD, regulamento que orienta as atividades e carga horária de trabalho do professor EBTT do IFRO. Os dados apontam para a complexificação do trabalho do professor EBTT, que o impele a exercer atividades além da docência e demanda uma flexibilidade que corrobora os achados teóricos sobre a pressão psicológica exercida pelas demandas do modelo gerencial nas instituições de ensino que podem, sobremaneira, intensificar o trabalho do professor, criando tensão entre as exigências do modelo do capital flexível e das possibilidades humanas.

PALAVRAS CHAVE: Gerencialismo. Trabalho docente. Professor EBTT. Sofrimento.

\footnotetext{
${ }^{1}$ Instituto Federal de Educação, Ciência e Tecnologia de Rondônia (IFRO), Porto Velho - RO Brasil. Professor EBTT. Mestrando em Psicologia (MAPSI-UNIR). ORCID: <https://orcid.org/0000-0002-4961-7154>.E-mail: jorge.amorim@ifro.edu.br ${ }^{2}$ Universidade Federal de Rondônia (UNIR), Porto Velho - RO - Brasil. Docente do Programa de Pós-Graduação em Psicologia (MAPSI-UNIR). ORCID: <https://orcid.org/0000-0002-57285161 >. E-mail: vdalcastel@gmail.com

${ }^{3}$ Universidade Federal de Rondônia (UNIR), Porto Velho - RO - Brasil. Docente do Programa de Pós-Graduação em Psicologia (MAPSI-UNIR). ORCID: <https://orcid.org/0000-0002-42704511>.E-mail: lumatospvh@ hotmail.com

RPGE- Revista on line de Política e Gestão Educacional, Araraquara, v. 22, n. 3, p. 1217-1232, set./dez., 2018. E-ISSN: $1982-5587$. DOI: $10.22633 /$ rpge.v22i3.11894 
RESÚMEN: Este artículo tiene como objetivo discutir el trabajo del profesor de Enseñanza Básica, Técnico y Tecnológico (EBTT) del Instituto Federal de Educación, Ciencia y Tecnología de Rondônia (IFRO), a partir del análisis del Reglamento de la Actividad Docente (RAD), buscando comprender su relación con las demandas del sistema neoliberal y el modelo gerencial en la educación. Como apoyo a nuestro estudio, buscamos fundamentos en algunos conceptos de Dejours (2007), tales como sufrimiento y placer en el trabajo, de Bauman (2005) sobre la modernidad, de Antunes y Praun (2015) salud y trabajo y Sennett (2009) del nuevo capitalismo para el carácter del trabajador. Además, traemos Pacheco (2010) para discutir las cuestiones relacionadas con los Institutos Federales de Educación, Ciencia y Tecnología y los Profesores EBTT, así como la Ley de creación de los Institutos Federales - Ley $n^{\circ} 11.892$ / 2008. Esta investigación se caracteriza como una investigación bibliográfica-documental que, aún del levantamiento teórico de los conceptos relacionados, analizó la Resolución 33/2017 que instituyó el $R A D$, reglamento que orienta las actividades y carga horaria de trabajo del profesor EBTT del IFRO. Los datos apuntan a la complejización del trabajo del profesor EBTT, que lo impulsa a ejercer actividades más allá de la docencia y demanda una flexibilidad que corrobora los hallazgos teóricos sobre la presión psicológica ejercida por las demandas del modelo gerencial en las instituciones de enseñanza que pueden, sobre todo, intensificar el trabajo del profesor, creando tensión entre las exigencias del modelo del capital flexible y de las posibilidades humanas.

PALABRAS CLAVE: Gerencialismo. Trabajo docente. Profesor EBTT. El sufrimiento.

ABSTRACT: This paper aims at discussing the Vocational Education and Training Teacher' work at the Federal Institute of Education, Science and Technology of Rondônia (IFRO), based on the analysis of the Teaching Activity Regulation, in an attempt to understand its relations with the demands from the neoliberal system the and the managerial model in education. To support our study, we have used concepts by Dejours (2007) concerning suffering and pleasure at work, Bauman (2005) on modernity, Antunes and Praun (2015) on health and work, and Sennett (2009) regarding the consequences of the new capitalism for the workers' character. In addition, we have brought Pacheco (2010) to discuss issues related to the Federal Institutes of Education, Science and Technology and the Vocational Education and Training (VET) Teachers, as well as the law that established the creation of the Federal Institutes (law n. 11.892/2008). This is a bibliographic-documental research that, in addition to the theoretical survey of related concepts, has analyzed the resolution $n$. 33/2017, which established the teaching activity regulations, and guides the activities and workload of the VET teacher at IFRO. Data have pointed to the complexity of VET Teachers' work, who is responsible for performing activities beyond teaching, which demands flexibility and corroborates the theoretical findings on the psychological pressure exerted by the managerial model demands in the educational institutions that might, considerably, intensify teachers' work, creating tension between the flexible capital model condition and the human possibilities.

KEY WORDS: Managerialism. Teaching work. Professor EBTT. Suffering. 


\section{Introdução}

Com a lei de criação dos Institutos Federais de Educação, Ciência e Tecnologia do Brasil, lei $\mathrm{n}^{\mathrm{o}} 11.892$, de 29 de dezembro de 2008, inaugura-se um novo cenário para a Educação Profissional e Tecnológica (EPT), com a oferta de várias modalidades de cursos, dentre elas o curso técnico integrado ao Ensino Médio, o curso técnico subsequente ao Ensino Médio, bacharelados, licenciaturas e pós-graduação lato-sensu e stricto-sensu.

A lei de criação dos Institutos Federais (IFs) trouxe exigências de um professor que ainda não havia sido pensado no Brasil, com um conjunto de competências que atenda diferentes níveis de ensino (do Ensino Médio à pós-graduação), públicos e faixas etárias. Essa nova classe é denominada Professor da Educação Básica, Técnica e Tecnológica, o "Professor EBTT". Permeado por demandas de uma política neoliberal, o trabalho do Professor EBTT abrange modalidades diversificadas, atendimento a um público diversificado e ações que se estendem ao Ensino, à Pesquisa, à Extensão e às atividades de apoio à administração.

Muitas alterações na sociedade a partir do século XX surgiram da crise econômica advinda da saturação do chamado Estado de Bem-Estar Social, o que demandou uma nova forma de organização do capital e uma administração pública mais flexível, menos centralizada, menos burocrática, mais produtiva, eficiente e eficaz (ARAÚJO; CASTRO, 2011). Nessa perspectiva surge o modelo gerencial, do inglês New Public Management, que trouxe consigo a proposição da elaboração de indicadores de desempenho para mensurar a eficiência e a eficácia dos trabalhadores inseridos nos modos produtivos do sistema capitalista. Da mesma forma, tal ação passou a ser aplicada também para o trabalho docente, que passou a acumular cada vez mais tarefas.

Neste artigo objetivamos discutir o trabalho do professor do Ensino Básico, Técnico e Tecnológico (EBTT) do Instituto Federal de Rondônia, a partir da análise do Regulamento da Atividade Docente (RAD), buscando compreender sua relação com as demandas do sistema neoliberal e o modelo gerencial na educação.

Sendo assim, apresentamos na sequência, uma discussão teórica sobre o modelo gerencial e as repercussões na personalidade do trabalhador, ou seja, na subjetividade do indivíduo, elucidando os reflexos desse modelo aplicado à educação e ao trabalho do professor EBTT, a partir da análise de suas atividades previstas no Regulamento das Atividades Docentes (RAD) do IFRO.

RPGE- Revista on line de Política e Gestão Educacional, Araraquara, v. 22, n. 3, p. 1217-1232, set./dez., 2018. E-ISSN: $1982-5587$. 


\section{O modelo gerencial e as repercussões na subjetividade do trabalhador}

A Nova Gestão Pública (NPG), do inglês New Public Management, também chamado de Modelo de Gestão Gerencial, surgiu da crise econômica do Estado de BemEstar Social, o Welfare State, que se deu no período pós-guerra, resultando na necessidade de reorganizar o capital. A partir disso, o modelo empresarial tornou-se referência, por apresentar um padrão mais flexível e ágil, ensejando critérios de eficiência, eficácia e produtividade (ARAÚJO; CASTRO, 2011) e influenciou a elaboração de políticas públicas na educação, saúde e segurança.

Araújo e Castro (2011) explicam o processo de reorganização das funções do Estado, que passou de um modelo baseado nas políticas keynesianas, reguladas pelo modelo burocrático weberiano, ao modelo gerencial. As políticas keynesianas garantiam o Estado de Bem-Estar Social - políticas para a área social, compreendendo a educação, saúde, moradia, previdência etc. Para regular essas ações, o Estado adotou o modelo burocrático weberiano, o qual apresentava características de impessoalidade, neutralidade e racionalidade. Com a "saturação" desse modelo e a crise econômica, surge o modelo gerencial, de caráter neoliberal, inspirado na "lógica de mercado" e nas características de agilidade, eficiência, produtividade, agilidade, qualidade na prestação de serviços, o que não implicou, no entanto, na extinção do modelo burocrático, que fora incorporado.

Ao compreender que o Modelo de Gestão Gerencial, "New Public Management", é orientado e regido pelas demandas do neoliberalismo, no qual a defesa do capital, direito ao lucro e propriedade privada são as prioridades, evidencia-se a busca pela eficiência e eficácia nas organizações, ou seja, as empresas públicas e privadas são impelidas a inovar, empreender no sentido de desempenhar as mesmas atividades e trazer cada vez mais resultados com o dispêndio de menos recursos. Tais ações, conforme Araújo e Castro (2011) comentam, estimulam a competição, o individualismo e até o egoísmo entre os indivíduos.

É interessante também argumentar que o modelo gerencial não supera a versão burocrática da administração pública, conforme explicam Araújo e Castro (2011), mas a torna mais flexível. Sendo assim, do trabalhador não é exigido somente a eficiência, eficácia e produtividade, mas também atender aos procedimentos burocráticos enraizados nas instituições educacionais e nas demais instituições.

Neste sentido, Gaulejac (2011) afirma que a NPG “[...] exerce uma pressão psicológica intensa sobre os trabalhadores (p. 84)". Isso ocorre porque, segundo ele, 
demandas conflitantes são produzidas pelo sistema, expondo os trabalhadores às pressões da lógica do modelo gerencial da busca incessante pela produtividade, eficiência e eficácia, submetendo-os a um ambiente altamente estressante, por ser individualista e excludente e considera-los como "um recurso" disponível. Alinhado a essa ideia, Sennett (2009) argumenta que o capitalismo moderno concebe o indivíduo como um recurso "descartável”, gerando profundo sofrimento devido a essa indiferença com que enxerga o ser humano e sua subjetividade.

Sennett (2009) relaciona a característica de flexibilidade do sistema gerencial à ansiedade experimentada por um indivíduo inserido nessa lógica do mercado. Isso acontece porque "[...] as pessoas não sabem que riscos serão compensados, que caminhos seguir. (p. 9)". A flexibilidade aparece a partir de um discurso sedutor de liberdade e controle sobre a própria vida, maquiando suas repercussões no caráter do indivíduo, entendido aqui como "[...] valor ético que atribuímos aos nossos próprios desejos e às nossas relações com os outros (p. 10)". Sendo assim, o termo é ainda mais abrangente que personalidade; conforme explica Sennett (2009), refere-se às questões internas, latentes no indivíduo.

O modelo de "capital flexível” tem gerado a "corrosão do caráter", ou seja, um profundo esfacelamento da subjetividade do indivíduo, explica Sennett (2009), que supostamente tem mais autonomia sobre sua atividade laboral, mas que a ele não pertence mais o tempo para consolidar o processo de construção de sua subjetividade, condição imprescindível, tendo em vista que a vida moderna está pautada no imediato ou, ainda, como explica Bauman (2009) na liquidez dos acontecimentos, fluídos e dispersos, fragmentando a subjetividade do indivíduo.

Neste contexto, Antunes e Praun (2015, p. 412) também abordam a relação entre flexibilidade (ou flexibilização) e o adoecimento do trabalhador.

[...] a flexibilização se expressa na diminuição drástica das fronteiras entre atividade laboral e espaço da vida privada, no desmonte da legislação trabalhista, nas diferentes formas de contratação da força de trabalho e em sua expressão negada, o desemprego estrutural.

O desmonte da legislação trabalhista discutido por Antunes e Praun (2015) começa nos anos de 1990 e continua progredindo em desfavor do trabalhador e em prol do adoecimento individual e coletivo, na medida em que complexifica o trabalho e atravessa a fronteira da vida privada. Neste sentido, somos levados a pensar nas novas tecnologias digitais da informação e comunicação que, na medida em que quebram fronteiras de 
espaço e tempo, também ultrapassam os limites entre atividades laborais e pessoais, constituindo-se, desta forma, como fortes aliadas às características do modelo gerencial de produtividade e flexibilidade.

As tecnologias são utilizadas progressivamente em escalas geométricas na busca da multiplicação do capital, subordinação sob a qual toda a sociedade capitalista encontra-se submetida. Com o avanço da tecnologia, acreditava-se que o sofrimento no trabalho poderia ser diminuído, considerando a modernização das operações e auxílio de máquinas e softwares (DEJOURS, 2007).

Dejours (2007) assevera que atrelada à tecnologia está o sofrimento dos trabalhadores que são submetidos a um controle cada vez mais preciso e mensurável da performance de suas atividades de trabalho, considerando prazos, metas e indicadores. A exigência da formação continuada é outro aspecto posto ao trabalhador que deve adquirir conhecimentos práticos e teóricos demandados pela evolução tecnológica, que cresce exponencialmente, impondo assim, adaptação e readaptação em um processo sem fim frente às novas relações mercadológicas estabelecidas com o avanço da tecnologia. $\mathrm{O}$ autor aponta que o trabalhador, nesse contexto, sofre por estar ininterruptamente buscando atender às expectativas que vem se complexificando com as novas e crescentes demandas do trabalho radicalmente e tecnologicamente controlado e mensurado. Sendo assim, por trás de tudo o que nossos olhos veem, além do que é intencionalmente apresentado e omitido, há o sofrimento do trabalhador.

Os novos modelos de gestão tendem a impor aos trabalhadores formas sutis de exigências, de performances ou resultados que vão além das possibilidades físicas e psíquicas dos mesmos. As vitrines são estratégias de banalização do mal, das péssimas condições de trabalho e saúde que vivenciam no dia-a-dia os trabalhadores (DEJOURS, 2007).

Mesmo que as pessoas se acostumem com novas rotinas, outras são colocadas com a rápida modernização e criação de novas tecnologias. Neste sentido, Bauman (2009) nos apresenta a noção de que existe um tempo para que o ser humano consolide sua vida/identidade, através de hábitos e rotinas. O autor chama nossa atenção para percebermos que nesta sociedade denominada por ele de "líquida moderna", as condições sobre as quais agem seus membros, mudam em um tempo mais curto do que o necessário para que tal consolidação seja realizada, o que pode gerar sofrimento e até o sentimento de culpa. A mesma ideia é defendida por Sennett (2009) que pontua a necessidade do tempo, do estabelecimento da relação com os acontecimentos internos e externos para a 
construção do caráter, ou seja, do valor individual que atribuímos aos nossos traços pessoais e pelos quais buscamos a valorização dos outros. A partir do momento que esse tempo nos é extirpado, somos impedidos de construir nossa subjetividade.

Segundo Bauman (2009), “[...] as condições de ação e as estratégias de reação envelhecem rapidamente e se tornam obsoletas antes dos atores terem uma chance de aprende-las efetivamente [...]" (p.07). As rápidas mudanças demandadas pelas tecnologias causam rupturas de padrões no trabalho, daí a demanda da flexibilização e adaptabilidade trazida pelo modelo gerencial, colocando o trabalhador, no caso do nosso estudo, do professor, em constante senso de prontidão e urgência.

Assim, percebemos que as características exigidas do trabalhador, sua habilidade para operar novos sistemas e ferramentas e gerar lucro, tornam-se mais importantes que o próprio indivíduo. Neste sentido, Gaulejac (2011) afirma que a ideologia gerencial concebe o indivíduo tão somente como um recurso: “[...] o indivíduo é instrumentalizado para serventia dos objetivos financeiros, operatórios, técnicos que o fazem perder o sentido de sua ação, que o fazem perder até o sentido de sua existência [...]” (p. 91). Segundo o autor, há uma ruptura entre o indivíduo visto e tratado como recurso para atingir objetivos organizacionais e o indivíduo com sua subjetividade. Por um lado, há a aceitação da submissão às exigências do empregador e, por outro, há uma porção do próprio indivíduo que resiste à instrumentalização.

Nesta direção, Antunes e Praun (2015) explicam que a implantação de estratégias do gerencialismo, como por exemplo o salário vinculado à produtividade, trouxe como consequências “[...] a flexibilização, a informalidade e a profunda precarização das condições de trabalho e vida da classe trabalhadora brasileira" (p. 409).

Toda a argumentação sobre o modelo gerencial, suas características e repercussões nos diversos segmentos sociais e na subjetividade do trabalhador, se aplica também à educação e ao trabalho do professor, tendo em vista que esse modelo influenciou e continua a influenciar a elaboração de políticas públicas para a educação e reflete nos modelos de gestão escolar, de formação de professores e na complexificação do trabalho docente.

O modelo gerencial repercutiu no campo educacional, conforme explicam Araújo e Castro (2011), através das políticas públicas que estabelecem modelos de gestão mais descentralizados como, por exemplo, a gestão democrática, a qual prevê descentralização das atividades e responsabilização, do inglês accountability. Com essa descentralização, as tarefas gerenciais são distribuídas entre os trabalhadores da educação, resultando em uma RPGE- Revista on line de Política e Gestão Educacional, Araraquara, v. 22, n. 3, p. 1217-1232, set./dez., 2018. E-ISSN: $1982-5587$. DOI: $10.22633 /$ rpge.v22i3.11894 
sobrecarga do trabalho docente que se estende além das atividades puramente de ensino, mas incorporam diversas outras atividades. Com a responsabilização, aos indivíduos são direcionadas as exigências para cumprimento de metas e alcance de indicadores de desempenho, podendo gerar um sentimento de "culpa" quando não conseguem.

Outra forte característica do modelo gerencial observada nas instituições públicas de ensino, tanto nas Universidades quanto nos IFs é o estabelecimento de metas ligadas à captação de recursos externos. Neste sentido, Ribeiro e Leda (2016) argumentam que as políticas de educação superior implementadas a partir dos anos de 1990 indicam que a privatização da universidade estatal está em franca expansão. Podemos perceber que, com a diminuição de aplicação de recursos governamentais, as instituições educacionais buscam, cada vez mais, ajustarem-se às demandas e leis de mercado e, por assim ser, estabelecem ações e operações que possibilitem a captação de recursos externos, a partir de convênios e contratos de parceria com a iniciativa privada, o que as aproxima das características de gestão de empresas privadas, ou seja, do modelo gerencial. No contexto das instituições de ensino superior ou EPT, essa captação de recursos é também uma tarefa muitas vezes atribuída ao professor.

A seguir, discutiremos mais especificamente como o modelo gerencial aplicado à educação reflete no trabalho do professor EBTT.

\section{Implicações do gerencialismo no trabalho do Professor do Ensino Básico, Técnico e Tecnológico (EBTT)}

A lei de criação dos Institutos Federais de Educação, Ciência e Tecnologia, lei n ${ }^{\circ}$ 11.892, de 29 de dezembro de 2008, apresenta as finalidades e objetivos (Quadro 1) para os quais eles foram criados. Tais finalidades e objetivos são diversos e abrangem a oferta de diferentes modalidades de cursos e níveis que atendam as demandas socioeconômicas, gerando emprego, renda e inovações tecnológicas que possam avançar a economia do Brasil (BRASIL, 2008). 
Quadro 1 - Finalidades e objetivos dos Institutos Federais de Educação, Ciência e Tecnologias

\begin{tabular}{|c|c|}
\hline Finalidades & Objetivos \\
\hline $\begin{array}{l}\text { I - ofertar várias modalidades da Educação } \\
\text { Profissional e Tecnológica (EPT) para atender às } \\
\text { demandas socioeconômicas regionais e } \\
\text { nacionais; } \\
\text { II - desenvolver a EPT como processo formativo } \\
\text { e investigativo para gerar e adaptar soluções } \\
\text { técnicas de acordo com as demandas } \\
\text { sociais/regionais; } \\
\text { III - promover integração e verticalização do } \\
\text { ensino, otimizando o aproveitamento dos } \\
\text { recursos humanos e materiais; } \\
\text { IV - orientar sua oferta em benefício da } \\
\text { consolidação/fortalecimento dos Arranjos } \\
\text { Produtivos, sociais, e culturais locais; } \\
\text { V - constituir-se como centro de excelência no } \\
\text { ensino de Ciências, geral e aplicadas; } \\
\text { VI - ser referência no apoio ao ensino de } \\
\text { ciências nas instituições públicas de ensino e } \\
\text { ofertar capacitação/atualização pedagógica aos } \\
\text { docentes da rede pública de ensino; } \\
\text { VII - desenvolver programas de extensão e } \\
\text { divulgação científica/tecnológica; } \\
\text { VIII - realizar/estimular a pesquisa aplicada, } \\
\text { produção cultural, empreendedorismo, } \\
\text { cooperativismo, } \\
\text { científico/tecnológico; } \\
\text { IX - promover a produção/desenvolvimento e } \\
\text { transferência de tecnologias. }\end{array}$ & $\begin{array}{l}\text { I - ministrar a educação profissional de } \\
\text { nível médio (cursos integrados, técnicos } \\
\text { e Educação de Jovens e Adultos); } \\
\text { II - ministrar cursos de formação inicial } \\
\text { e continuada (FIC) para trabalhadores } \\
\text { (capacitação, aperfeiçoamento, } \\
\text { especialização, atualização) em todos os } \\
\text { níveis de escolaridade; } \\
\text { III - realizar pesquisas aplicadas; } \\
\text { IV - desenvolver atividades de extensão; } \\
\text { V - Estimular e apoiar processos } \\
\text { educativos que levem à geração de } \\
\text { trabalho e renda; e } \\
\text { VI - Ministrar em nível de educação } \\
\text { superior: a) cursos superiores de } \\
\text { tecnologia; b) cursos de licenciatura, } \\
\text { bem como programas especiais de } \\
\text { formação pedagógica, c) cursos de } \\
\text { bacharelado e engenharia; d) cursos de } \\
\text { pós-graduação lato sensu de } \\
\text { aperfeiçoamento e especialização; e) } \\
\text { cursos de pós-graduação stricto sensu de } \\
\text { mestrado e doutorado. }\end{array}$ \\
\hline
\end{tabular}

Fonte: Resumo elaborado pelo autor a partir da Lei $\mathrm{n}^{\circ} 11.892$, de 29 de dezembro de 2008.

É possível perceber que as finalidades e objetivos dos IFs fazem parte do projeto econômico do país e alinham-se com as demandas do modelo gerencial na educação. Neste contexto, ao professor ETBB as exigências de atuação se colocam em diversos sentidos, tanto na promoção do ensino, quanto na pesquisa, extensão e apoio administrativo. Observa-se a necessidade deste professor ser polivalente, atuar com excelência do nível médio até a Pós-graduação, com atividades de ensino, pesquisa e extensão.

Segundo Pacheco (2010), os Institutos Federais surgiram no cenário nacional com a missão de revolucionar e educação profissional e tecnológica, “[...] visando ampliar a oferta de cursos técnicos, sobretudo na forma de ensino médio integrado, inclusive utilizando a forma de educação a distância $(\mathrm{EaD})[\ldots]$ ” (p. 15). Ele afirma, ainda, que as práticas dessa instituição estão pautadas na prevalência do bem social sobre os demais interesses e assim consolidam seu papel junto à sociedade. Essas instituições, "[...] na 
construção de uma rede de saberes que entrelaça cultura, trabalho, ciência e tecnologia em favor da sociedade, identificam-se como verdadeiras incubadoras de políticas sociais [...]" (p. 16).

Ao tomar ciência das variadas finalidades e objetivos dos Institutos Federais, bem como das expectativas sob as quais o projeto está submetido, pode-se compreender, mais facilmente, as demandas que são endereçadas à classe de Professores EBTT. Tais demandas são reflexo do modelo gerencial, que acabam por intensificar a carga de trabalho do professor, construídas sob a ilusão de flexibilidade e autonomia do trabalho.

Neste sentido, Tardif e Lessard (2014) explicam como é difícil revelar as condições, a carga de trabalho, as tarefas concretas, a duração e a variedade das atividades do professor. Muitas variáveis precisariam ser lavadas em conta ao analisar tais questões, tais como número de horas trabalhadas, os salários, os tamanhos das turmas etc.

Os autores ponderam sobre o fato do trabalho ser burocratizado e regulamentado, podendo, assim, apresentar-se limitado em relação à autonomia. Para eles, o resultado do trabalho vai depender do nível de envolvimento, responsabilidade e iniciativa dos professores. Desta forma, é possível perceber a característica de responsabilização pelos resultados.

A docência é apresenta por Tardif e Lessard (2014) como um trabalho parcialmente flexível, pois, algumas das funções são bem definidas no que diz respeito ao seu horário de trabalho, tais como a ministração de aulas, mas, quando se trata de encontro com os pais, reuniões, preparação de aulas e correções em geral, torna-se difícil mensurar tanto a complexidade do trabalho, quanto o tempo de duração que cada um tomará. Também devese levar em consideração a experiência do professor e o nível de desenvolvimento e comprometimento do mesmo, pois, não raramente, o profissional está em seu tempo pessoal refletindo sobre alunos ou até mesmo, a título de exemplo, assistindo um filme para assimilar uma cultura "jovem", do universo do seu aluno, dando a entender que o profissional está a todo e qualquer momento trabalhando, o que invariavelmente ultrapassa os limites da atividade laboral.

\section{Uma análise e discussão das atividades do Professor EBTT}

Neste item discutiremos como o trabalho do professor EBTT se organiza, a partir da análise do Regulamento de Atividade Docente (RAD), documento que objetiva normatizar a gestão das atividades docentes, aprovado através da Resolução n. ${ }^{\circ} 33$ - 
CONSUP/IFRO, de 02/06/2017. A cada semestre, é dever do professor EBTT preencher seu Registro de Atividade Docente, a partir do Sistema de Gerenciamento online SIGAedu, em conformidade com o Regulamento.

O RAD estabelece como atividades do professor EBTT: I. atividades de ensino; II. atividades de orientação; III. atividades de capacitação/qualificação; IV. atividades de pesquisa; V. atividades de extensão; VI. atividades de administração e representação. Cada atividade pode desdobrar-se em diversas outras, tendo em vista que apenas orientam a natureza da atividade, não sendo determinado o grau de complexidade de cada uma. Sendo assim, um professor com um regime de 40 horas de trabalho tem suas atividades distribuídas conforme o RAD. A seguir, apresentaremos no quadro 2 um resumo do anexo ao RAD, o qual apresenta 83 entradas de atividades do professor EBTT e determina uma duração em horas para cada uma.

\section{Quadro 2 - Resumo do RAD}

\section{REGULAMENTO DE ATIVIDADE DOCENTE}

(Total de 83 atividades nos itens ensino, orientação, capacitação/qualificação, pesquisa, extensão, administração/representação)

1. ENSINO - 14 possíveis atividades que resumidamente englobam: docência nas modalidades para ensino médio integrado, concomitante, subsequente, graduação e pós-graduação; coordenação de programa institucional, projetos interdisciplinares integradores; treinamento esportivo, artístico e/ou cultural; produção de material didático áudio/visual; supervisão de estágio docência de alunos de Cursos Superiores. Também se referem às atividades de manutenção do ensino, tais como o estudo, planejamento, preparação de aulas, elaboração de material didático e roteiros de aulas; elaboração e correção de instrumentos de avaliação; elaboração e programação de experimentos didáticos, manutenção, aferição, teste, projeto.

2. ORIENTAÇÃO - 19 possíveis atividades que resumidamente englobam: orientação ou coorientação de trabalho de especialização, trabalho de conclusão de curso de graduação, pósgraduação; curso técnico, iniciação científica e tecnológica; projeto de extensão etc.

3. CAPACITAÇÃO/QUALIFICAÇÃ̃O - 10 possíveis atividades que resumidamente englobam: estágio Pós-Doutoral, Stricto sensu, Pós-graduação com/sem afastamento; participação em eventos científicos, tecnológicos e culturais e demandas contínuas de formação para atender os anseios institucionais.

4. PESQUISA - 05 possíveis atividades que resumidamente englobam: coordenação de programa institucional de pesquisa com captação de recursos externos; pesquisa aprovado por órgãos/instituições/empresas de fomento; pesquisa de iniciação científica ou tecnológica devidamente aprovado pelo DEPESP ou PROPESP, ou Fundações de Amparo à Pesquisa (FAPs) etc.

5. EXTENSÃO - 07 possíveis atividades que resumidamente englobam: coordenação e/ou participação de programa institucional de extensão com captação de recursos externos ou aprovados por órgãos de fomento/ ou pela instituição; ministrante em cursos de extensão de curta duração, com carga horária inferior a 160 horas; produção de material áudio/visual, de cunho técnico-científico-cultural.

6. ADMINISTRAÇÃO/ REPRESENTAÇÃO - 28 possíveis atividades que resumidamente englobam: ocupação de cargos de gestão em reitoria, diretoria, coordenações, pró-reitora; chefia de departamento; assessoria e apoio à gestão, membro ou suplente de comissões internas ou externas ou de órgãos colegiados, membro de bancas de defesa/qualificação de trabalhos.

Fonte: Elaborado pelos autores a partir da Resolução n. ${ }^{\circ} 33$ - CONSUP/IFRO, de 02/06/2017

RPGE- Revista on line de Política e Gestão Educacional, Araraquara, v. 22, n. 3, p. 1217-1232, set./dez., 2018. E-ISSN: $1982-5587$. 
A carga horária para cada atividade pode variar, conforme a resolução, mas deve cumprir o mínimo/máximo de horas exigido. Assim, do professor é exigido que atue em ensino, carga horária predominante, na pesquisa, na extensão, que se qualifique continuamente para atender às demandas institucionais, determinadas pela dinâmica mercadológica, e que apoie a gestão.

Observamos no RAD a materialização do modelo gerencial, cujas características focadas na produtividade, agilidade e flexibilidade se sobrepõem ao fator humano, demandando esforços do indivíduo que vão além das fronteiras de sua individualidade, ignoram o tempo de execução e os limites entre a vida laboral e a vida pessoal. Dessa forma, entendemos que há um desequilíbrio no dimensionamento entre a demanda estabelecida e a capacidade humana de entrega do trabalho que o permita ter uma vida emocionalmente saudável, estabelecendo uma relação duradoura com sua subjetividade.

A partir da análise desse regulamento, somos levados a refletir sobre a natureza multifacetada do trabalho do professor EBTT, em especial aqueles que se enquadram no regime de trabalho 40 horas semanais de dedicação exclusiva. Apesar de o RAD estabelecer uma carga horária para cada cabeçalho de atividade docente apresentada, concordamos com Tardif e Lessard (2014) quando afirmam que a duração das tarefas do professor é dificilmente mensurada.

Para cada atividade, observamos que há muitas demandas, que requerem conhecimentos, competências e habilidades variadas. Para o ensino, além de dar aulas e desempenhar funções de manutenção do ensino, como planejar, preparar materiais para aula, avaliar etc., também fazem parte a coordenação de atividades esportivas, culturais e artísticas, a produção de materiais e supervisão de estágios de docência.

Além disso, é exigido do professor EBTT uma elasticidade quanto ao segmento e nível de ensino, abrangendo o Ensino Básico, a graduação e a pós-graduação, com um público diversificado, com foco e faixas etárias distintas. Da mesma forma, em relação à orientação, o professor também deve atender os diferentes níveis, seja relacionado à iniciação científica, ao trabalho de conclusão de cursos técnicos, de especialização, de graduação ou pós-graduação.

A qualificação do professor estabelecia no RAD está intimamente ligada à dinâmica do modelo gerencial, pois já que os processos, tecnologias e demandas mercadológicas estão em constantes e rápidas mudanças, a preparação do docente também deve seguir o mesmo padrão. Além de ser uma exigência, para as metas institucionais 
sejam atingidas, a qualificação do professor está atrelada à possibilidade de progressão de sua carreira, ou seja, de aumento salarial.

As atividades de pesquisa lançam ao professor trabalhos que desenvolvam o conhecimento científico, bem como possibilitem a criação de convênios e projetos como fontes captadoras de recursos junto à iniciativa privada, o que reforça o comportamento orientado por resultados. Da mesma forma, as atividades de extensão, referentes à transferência de conhecimentos produzidos à comunidade externa, através de um conjunto diversificado de ações (projetos, programas, prestação de serviços, consultoria, assessoria, cursos etc.), também incentivam a captação de recursos externos.

Também se espera que o professor execute atividades de administração e representação que impõem, de certa forma, a complexificação e intensificação da carga de trabalho docente, bem como implica na necessidade de uma melhor formação desse profissional que ramifica e diverge sua atuação para além do ensino. A participação em comissões diversas exige do professor conhecimentos, habilidades e atitudes que, muitas vezes, podem conflitar com seus interesses e afinidades pessoais, como por exemplo, a participação em comissões de sindicância, podendo, inclusive, atravessar relacionamentos interpessoais na instituição.

\section{Considerações finais}

O objetivo deste estudo foi discutir o trabalho do professor do Ensino Básico, Técnico e Tecnológico (EBTT) do Instituto Federal de Rondônia, a partir da análise do Regulamento da Atividade Docente (RAD), buscando compreender sua relação com as demandas do sistema neoliberal e o modelo gerencial na educação.

Compreendemos que as demandas ao o professor EBTT não se desvinculam da forma como a sociedade se organiza em torno do capital. O modelo de gestão educacional repercute diretamente no trabalho do professor, determina suas ações e interfere em sua subjetividade.

Sendo assim, as atribuições dessa figura multitarefas estão alinhadas às demandas do sistema neoliberal e ao modelo gerencial na educação, no que tange às características de eficiência, eficácia, agilidade e produtividade, em todos os tipos de atividades, sejam essas relacionadas ao ensino, à pesquisa, à extensão, às atividades administrativas, à orientação de alunos ou à própria qualificação, exigindo do professor o alcance de metas institucionais pré-estabelecidas que atendam aos respectivos avaliadores de desempenho. 
É possível perceber a partir da discussão teórica e análise do RAD que, embora haja um "protocolo" a ser executado com o registro das atividades, o instrumento apresenta-se como uma exigência para o cumprimento de tarefas burocráticas que não são capazes de revelar e traduzir, de fato, a carga horária e o trabalho do professor EBTT, do qual é exigido uma elasticidade para atender diferentes segmentos, públicos, faixas etárias e demandas. Neste sentido, corroboramos os achados de Araújo e Castro (2011), quando argumentam que o modelo gerencial não superou o modelo burocrático, mas o incorporou, criando demandas mais complexas.

As entradas do anexo ao RAD, que especificam alguns tipos de atividades do professor e determinam uma duração para execução de cada uma, são generalizações incapazes de expressar, por seu caráter de meros cabeçalhos, os limites quantitativos e qualitativos do trabalho docente, conforme apontados por Tardif e Lessard (2014).

A quantificação de horas pré-estabelecidas para as atividades pode ser inadequada, uma vez que os esforços para cada circunstância são desconhecidos. Ao quantificar as horas, a eficácia, eficiência e produtividade do processo gerencial são prepostos em detrimento do fator humano, de sua subjetividade, do tempo necessário para estabelecer uma relação de sentido com sua atividade laboral, consigo e com outras pessoas.

É consenso na teoria da administração pública ou privada que qualquer organização deve aplicar seus recursos, pessoal, material, processual e financeiro, de forma adequada e criteriosa para atingir seus objetivos, e avaliar os resultados para evitar desperdício de qualquer ordem (CHIAVENATO, 2011). Ao apresentarmos as repercussões do modelo gerencial no trabalho docente e na vida do professor, não estamos ignorando a necessidade do estabelecimento de processos administrativos que envolvam a racionalização e avaliação da aplicação de recursos, considerando a escassez e limitações. No entanto, alertamos para as indicações de colapso que o sistema capitalista tem apresentado, evidenciando uma disparidade entre a exigência do capital e a possibilidade humana. Desta forma, torna-se necessário aprofundar as reflexões e pesquisas em busca de soluções e estratégias de enfrentamento que possam reduzir a sobrecarga do trabalho docente.

\section{REFERÊNCIAS}

ANTUNES, Ricardo; PRAUN, Luci. A sociedade dos adoecimentos no trabalho. Serv. Soc. Soc; São Paulo, n. 123, p. 407-427, jul./set. 2015. 
ARAÚJO, Suêldes de; CASTRO, Alda Maria Duarte Araújo. Gestão educativa gerencial: superação do modelo burocrático? Ensaio: Aval. pol. públ. Educ., Rio de Janeiro, v. 19, n. 70, p. 81-106, jan./mar. 2011. Disponível em:

http://www.scielo.br/pdf/ensaio/v19n70/v19n70a06.pdf . Acesso: 10 maio 2018.

BAUMAN, Zigmund. Vida líquida. Tradução Carlos Alberto Medeiro. 2ed. Rio de Janeiro: Zahar, 2009.

BRASIL. Lei de criação dos Institutos Federais de Educação, Ciência e Tecnologia - Lei n' 11.892, de 29 de dezembro de 2008. Disponível em: http://www.planalto.gov.br/ccivil_03/_ato2007-2010/2008/lei/111892.htm. Acesso: 18 maio 2018.

CHIAVENATO, Idalberto. Introdução à Teoria Geral da Administração. 8. ed. Rio de Janeiro: Elsevier, 2011.

DEJOURS, Christophe. A banalização da injustiça social. Rio de Janeiro: Editora FGV, 2007.

GAULEJAC, V. A NGP: a nova gestão paradoxal. In: BENDASSOLLI, P. F.; SOBOLL, L. A. P. (Orgs). Clínicas do trabalho: Novas perspectivas para compreensão do trabalho na atualidade. São Paulo: Atlas, 2011, p. 84-98.

IFRO. Resolução n. ${ }^{\circ}$ 33/REIT - CONSUP/IFRO, de 02 de junho de 2017 - Regulamento de Atividades Docentes - RAD do Instituto Federal de Educação, Ciência e Tecnologia de Rondônia. Disponível em:

http://www.ifro.edu.br/consup/index.php?option=com_docman\&task=doc_details\&gid=85 9\&Itemid=11. Acesso: 12 maio 2018.

PACHECO, Eliezer Moreira. Os Institutos Federais: uma revolução na Educação Profissional e Tecnológica. Natal: IFRN, 2010.

RIBEIRO, Carla Vaz dos Santos e LEDA, Denise Bessa. O trabalho docente no enfrentamento do gerencialismo nas Universidades Federais Brasileiras: repercussões na subjetividade. Educação em Revista, 2016, vol.32, n.4, pp.97-117. ISSN 0102-4698. Disponível em: http://www.scielo.br/pdf/edur/v32n4/1982-6621-edur-32-04-00097.pdf. Acesso em: 05 jul. 2018.

SENNETT, Richard. A corrosão do caráter: consequências pessoais do trabalho no novo capitalismo. 14. ed. Rio de Janeiro: Record, 2009.

TARDIF, Maurice e LESSARD, Claude. O trabalho docente: elementos para uma teoria da docência como profissão de interações humanas. Tradução de João Batista Kreuch. 9. Ed. Rio de Janeiro: Vozes, 2014. 


\section{Como referenciar este artigo}

AMORIM JR, Jorge Washington de; SCHLINDWEIN, Vanderléia de L. Dal Castel; MATOS, Luís Alberto Lourenço de. O Trabalho do Professor EBTT: entre a exigência do capital e a possibilidade humana. Revista on line de Política e Gestão Educacional, Araraquara, v. 22, n. 3, p. 1217-1232, set./dez., 2018. E-ISSN: 1982-5587. DOI: 10.22633/rpge.v22i3.11894

Submetido em: 08/05/2018

Aprovado em: 30/07/2018

RIAEE - Revista Ibero-Americana de Estudos em Educação, Araraquara, v. 22, n. 3, p. 1217-1232, set./dez., 2018. E-ISSN: 1982-5587. 